\title{
RAS Gene Polymorphisms and Renal Responsiveness to RAS Inhibition Therapy in Type 2 Diabetic Asian Indians
}

Balneek Singh Cheema ${ }^{1}$, Harbir Singh Kohli ${ }^{2}$, Rajni Sharma ${ }^{1}$, Viral N Shah ${ }^{3}$, Sreenivasan lyengar ${ }^{2}$, Anil Bhansali $^{3}$ and Madhu Khullar ${ }^{1 *}$

${ }^{1}$ Department of Experimental Medicine and Biotechnology, Post Graduate Institute of Medical Education and Research, Chandigarh 160012, India

${ }^{2}$ Department of Nephrology, Post Graduate Institute of Medical Education and Research, Chandigarh 160012, India

${ }^{3}$ Department of Endocrinology, Post Graduate Institute of Medical Education and Research, Chandigarh 160012, India

\begin{abstract}
Objective: Inhibitors of renin angiotensin system (RAS), ACE inhibitors (ACEI) and angiotensin II receptor blockers (ARBs), are frequently used as renal-protective agents in type 2 diabetes (T2D). However, there is significant inter individual variability in response to these drugs. In the present study, we examined the role of genetic polymorphisms in ACE, AGT and AGTR1 genes, in modulating reno-protective response to ACEI and ARB therapy in north Indian T2DM subjects, with cases having diabetic nephropathy (DN) and controls without DN.
\end{abstract}

Method: 810 north Indian T2D patients treated with ACEI or ARB after diagnosis were followed up for 3 years. Percent changes in eGFR, urinary albumin excretion (UAE), serum creatinine at the end of 3 years of treatment were taken as points of renoprotective response.

Result: We observed that $A C E$ II genotype and cumulative risk score of $<1$ was associated with better renoprotective response to ACEI in T2D, with normoalbuminuria $(p<0.05)$. Whereas in T2D with micro/macroalbuminuria, DD genotype $(A C E \mathrm{I} / \mathrm{D})$ and a risk score of $>6$ was associated with better renoprotective response to $A R B(p<0.05)$.

Conclusion: Our results suggest that $A C E \mathrm{I} / \mathrm{D}$ genotypes individually and in interaction with other RAS SNPS modulate renoprotective efficacy of ACEI and ARB in T2D patients, depending on the status of proteinuria.

Keywords: RAS gene polymorphisms; RAS inhibition therapy; Type 2 diabetes; Diabetic nephropathy

\section{Introduction}

Type 2 diabetes (T2D) is the most common cause of nephropathy, accounting for nearly $44 \%$ of renal failure cases [1,2]. In addition, in spite of adequate glycemic and blood pressure control, progression to renal failure in T2D patients is highly variable, indicating interplay between genetic and other predisposing factors in the development of the kidney disease in diabetic patients [3-5].

The renin-angiotensin system (RAS) has been strongly implicated in the pathogenesis of progressive renal diseases, including DN and inhibitors of RAS: Angiotensin converting enzyme inhibitors (ACEI) and angiotensin II receptor blockers (ARBs) are frequently used as renal-protective agents in T2D patients [6]. ACEI and ARB therapy is known to improve glomerular function, prevent proteinuria, and exerts beneficial effects on the progression of renal disease [7]. However, there is significant inter individual variability in responses to RAS inhibition by ACEI, or/and ARB. Studies over the past decade have shown that polymorphisms in RAS genes such as Angiotensin-converting enzyme $(A C E)$, Angiotensinogen $(A G T)$, and Angiotensin II type I receptor (AGTR1) may partly influence the observed inter individual variation, in response to RAS blockade [8-14]. It has been suggested that genetic variants, which have an association with the local tissue activity of RAS in diseased kidney, may also determine the responsiveness to ACE I/ ARB $[15,16]$. The most common candidate gene variant proposed to date to influence response to RAS inhibition is an insertion/deletion (I/D) polymorphism in the $A C E$, which has been shown to influence the concentration of ACE, both in circulation and local tissue [7]. Several studies have examined association of ACE polymorphism, renoprotection and response to RAS inhibition therapy in T2D, but results have been conflicting, contrasting and less consistent [17]. For example, reduction of endpoints in NIDDM with the Angiotensin II antagonist losartan (RENAAL) study, comprising 1513 patients showed
DD genotype to be associated with better response and higher risk reduction in end stage kidney disease (ESKD) [18], whereas a few studies with smaller sample size reported that response to ARB in T2D with renal disease was independent of $A C E$ I/D polymorphism [12-14]. A post hoc analyses of a large prospective, randomized, double blind, placebo-controlled clinical trial of RAS inhibitor therapy in diabetic proteinuric renal disease, where end stage kidney disease (ESKD) was the primary outcome variable, reported that DD and ID genotypes were associated with greater reduction in risk of ESKD with RAS inhibition therapy, whereas no treatment effect was observed in the II genotype carriers [19].

Although gene polymorphisms for other components of RAS, such as AGT and the AGTR1, have been shown to be associated with development and progression of $\mathrm{DN}$ in $\mathrm{T} 2 \mathrm{D}$, however, their role in modulating response to RAS inhibition therapy is not well studied. Dragović et al. [20] showed that 1166 A/C AGTR1 polymorphism was associated with the renoprotective response to ARB therapy in type 1 diabetic patients. Narita et al. [21] observed that M235T and A (-20) C genotype of $A G T$ could influence the therapeutic efficacy of a RAS blockade in immunoglobulin A nephropathy (IgAN). In a recent review, Konoshita [22] concluded that genetic variants of the RAS were not individually associated with antihypertensive effects by RAS blockade,

${ }^{*}$ Corresponding author: Dr. Madhu Khullar, Department of Experimental Medicine and Biotechnology, Post Graduate Institute of Medical Education and Research, Chandigarh 160012, India, Tel: 0091-09316131057; E-mail: madhu.khullar@gmail.com

Received April 22, 2013; Accepted April 24, 2013; Published April 30, 2013

Citation: Cheema BS, Kohli HS, Sharma R, Shah VN, lyengar S, et al. (2013) RAS Gene Polymorphisms and Renal Responsiveness to RAS Inhibition Therapy in Type 2 Diabetic Asian Indians. J Pharmacogenom Pharmacoproteomics 4:114. doi:10.4172/2153-0645.1000114

Copyright: (c) 2013 Cheema BS, et al. This is an open-access article distributed under the terms of the Creative Commons Attribution License, which permits unrestricted use, distribution, and reproduction in any medium, provided the original author and source are credited. 
Citation: Cheema BS, Kohli HS, Sharma R, Shah VN, lyengar S, et al. (2013) RAS Gene Polymorphisms and Renal Responsiveness to RAS Inhibition Therapy in Type 2 Diabetic Asian Indians. J Pharmacogenom Pharmacoproteomics 4: 114. doi:10.4172/2153-0645.1000114

Page 2 of 7

but could act synergistically to modulate drug response. The goal of our study was to investigate the association of gene polymorphisms of $A C E, A G T$ and AGTR1 genes, with reno-protective response to ACEI and ARB therapy in north Asian Indian T2D patients, with cases having $\mathrm{DN}$ and controls without DN. For this, we prospectively enrolled and genotyped T2D patients with and without nephropathy, on ACEI or ARB therapy from a large tertiary hospital of North India, and followed them up in renal clinic for 3 years for evaluating their renal responsiveness to therapy.

\section{Materials and Methods}

\section{Study population}

T2D patients of north Indian ethnicity attending the Endocrinology and Nephrology clinics were enrolled and followed up for a period of three years between January 2009 and March 2012. Their ethnicity was confirmed on the basis of language spoken, region of residence and ancestral history. All the patients were age, sex and ethnicity matched. No regional differences in disease prevalence or allele frequency were observed between recruitment sites. The inclusion criteria were as follow: age at onset of diabetes $>35$ years, T2D for more than or equal to 5 years, north Indian origin. Diabetes diagnosis was based upon WHO criteria with fasting plasma glucose $\geq 7.0 \mathrm{mmol} / \mathrm{l}$. Moreover, since the patients had T2D for 5 years or more, they were well characterized T2D patients and were under chronic treatment. Based upon the inclusion criteria, a total of 940 patients of age $>35$ years with mean duration of diabetes $(8.4 \pm 2.0)$ years were screened, and 810 subjects were finally included in the study, after excluding patients with a history of glomerulonephritis, microscopic hematuria, or known history of obstructive uropathy, such as renal stone on ultrasound scan from the study. Patients who were intolerant to ACEI, ARB, pregnant and lactating women, and patients taking aspirin and other non-steroidal antiinflammatory drugs (NSAIDS), were also excluded from the study. For each subject, detailed clinical history, biochemical and documentation of drug information were recorded. The study involved outpatient visits scheduled every 6 month. The study was approved by Post Graduate
Institute of Medical Education and Research, Chandigarh, ethics committee. Written informed consent was taken from all subjects for genetic testing, and the genetic tests to be performed were pre-specified at the time of the study design.

T2D subjects were divided into two groups: Group $1 \quad(n=490)$, consisted of patients without nephropathy (normoalbuminuria) and Group $2 \quad(n=320)$ consisted of patients with nephropathy (microalbuminuria, and/or macroalbuminuria). Patients were considered normoalbuminuric when their urinary albumin excretion rate (UAE) was $<30 \mathrm{mg} / 24$ hours. Patients whose UAE increased into the range of $30-300 \mathrm{mg} / 24$ hours were considered microalbumiuric. Patients having urinary albumin excretion rate greater than $300 \mathrm{mg} / 24$ hours were considered macroalbuminuric. Patients received ACEI or $\mathrm{ARB}$ after the diagnosis and during their clinical course as per the decision of treating physician; patients who were on combined therapy, or were initially treated with ACEI and then switched to ARB, or vice versa were excluded from the study. In Group 1, 318 patients were treated with ACEI and 172 were treated with ARB. In Group 2, 190 patients were treated with ACEI and 130 were treated with ARB. None of the enrolled patients were on combination therapy with both ACEI and ARB. Patients taking aldosterone antagonists and renin inhibitors were also excluded from the study. Although, Group 1 patients were normoalbuminuric, they were prescribed ACEI/ARB as all the Group 1 patients were diabetic, and ACEI and ARB are used as antihypertensive agents, and for preventing kidney damage in people with hypertension or diabetes (Table 1).

\section{Clinical response points}

The change in eGFR, urinary albumin excretion rate (UAE) and serum creatinine levels at baseline and end of 36 months of active treatment period were taken as primary points of response to RAS inhibition therapy. UAE and serum creatinine were measured by Hemocue and Roche autoanalyzer, respectively. eGFR was calculated by Modification of Diet in Renal Disease (MDRD) formula. GFR (mL/ $\left.\mathrm{min} / 1.73 \mathrm{~m}^{2}\right)=175 \times\left(\mathrm{S}_{\mathrm{cr}}\right)^{-1.154} \times(\text { Age })^{-0.203} \times(0.742$ if female $)$.

\begin{tabular}{|c|c|c|c|c|c|c|c|c|}
\hline \multirow[b]{2}{*}{$\begin{array}{l}\text { Base line characteristics } \\
\text { (Mean } \pm \text { SD) }\end{array}$} & \multicolumn{4}{|c|}{ Before Treatment } & \multicolumn{4}{|c|}{ After Treatment } \\
\hline & $\begin{array}{l}\text { Group } 1 \\
(n=490)\end{array}$ & $\begin{array}{l}\text { Group 2 } \\
(n=320)\end{array}$ & $\mathbf{P}$ & $\begin{array}{l}\text { Adjusted } \\
\text { P value }\end{array}$ & $\begin{array}{l}\text { Group } 1 \\
(n=490)\end{array}$ & $\begin{array}{l}\text { Group 2 } \\
(n=320)\end{array}$ & $\mathbf{P}$ & $\begin{array}{l}\text { Adjusted } \\
\text { P value }\end{array}$ \\
\hline Age (years) & $58.9 \pm 9.7$ & $55.7 \pm 9.1$ & $<0.001$ & 0.02 & $61.6 \pm 9.0$ & $58.8 \pm 9.0$ & 0.001 & 0.03 \\
\hline Males/Females (\%) & $225 / 265(46 / 54)$ & $134 / 186(42 / 58)$ & 0.9 & - & $225 / 265(46 / 54)$ & $134 / 186(42 / 58)$ & 0.9 & - \\
\hline $\begin{array}{l}\text { Time since diagnosis of } \\
\text { T2D (yrs) }\end{array}$ & $8.2 \pm 2.1$ & $8.7 \pm 2.9$ & 0.06 & - & $11.8 \pm 2.0$ & $11.6 \pm 3.0$ & 0.07 & - \\
\hline $\begin{array}{l}\text { Duration of HT } \\
\text { (years) }\end{array}$ & $5.5 \pm 3.9$ & $7.8 \pm 3.1$ & 0.001 & 0.04 & $8.3 \pm 3.6$ & $10.5 \pm 3.0$ & $<0.001$ & 0.03 \\
\hline S.B.P. (mm Hg) & $129.20 \pm 15.9$ & $135.44 \pm 21.1$ & 0.001 & 0.02 & $126.3 \pm 14.6$ & $130.6 \pm 20.0$ & 0.09 & 0.04 \\
\hline D.B.P. $(\mathrm{mm} \mathrm{Hg})$ & $80.5 \pm 6.9$ & $81.9 \pm 6.0$ & 0.15 & - & $80.1 \pm 4.5$ & $81.0 \pm 5.8$ & 0.2 & - \\
\hline BMI $\left(\mathbf{k g} / \mathbf{m}^{2}\right)$ & $25.8 \pm 4.0$ & $25.6 \pm 4.5$ & 0.6 & - & $24.6 \pm 3.5$ & $25.1 \pm 4.3$ & 0.7 & - \\
\hline HbA1c (\%) & $7.1 \pm 1.7$ & $7.7 \pm 2.1$ & 0.007 & 0.03 & $4.0 \pm 1.3$ & $4.4 \pm 2.0$ & 0.009 & 0.02 \\
\hline $\mathrm{Hb}(\mathrm{gm} / \mathrm{dl})$ & $11.4 \pm 1.6$ & $10.2 \pm 1.9$ & $<0.001$ & 0.01 & $12.0 \pm 1.3$ & $11.0 \pm 1.3$ & 0.009 & 0.01 \\
\hline TC & $260.3 \pm 63.7$ & $255.3 \pm 64.3$ & 0.89 & - & $171.4 \pm 40.7$ & $184.1 \pm 60.7$ & 0.14 & - \\
\hline TG (mg\%) & $207.6 \pm 38.3$ & $204.9 \pm 39.2$ & 0.86 & - & $164.9 \pm 71.2$ & $170.7 \pm 96.1$ & 0.9 & - \\
\hline HDL (mg\%) & $61.1 \pm 16.1$ & $63.5 \pm 15.1$ & 0.74 & - & $50.8 \pm 14.8$ & $52.6 \pm 13.8$ & 0.6 & - \\
\hline LDL-C (mg/dl) & $98.7 \pm 34.9$ & $100.4 \pm 41.8$ & 0.2 & - & $93.0 \pm 34.7$ & $96.6 \pm 43.9$ & 0.22 & - \\
\hline HDL-C (mg/dl) & $47.1 \pm 10.1$ & $48.9 \pm 20.6$ & 0.38 & - & $42.7 \pm 8.3$ & $43.6 \pm 12.3$ & 0.61 & - \\
\hline
\end{tabular}

( $p<0.05$ is significant) [BMI: Body Mass Index, HT: Hypertension, Hb: Hemoglobin, SBP: Systolic Blood Pressure, DBP: Diastolic Blood Pressure, T2D: Type 2 Diabetes, TC: Total Cholesterol, TG: Triglyceride, LDL-C: Low Density Lipoprotein Cholesterol, HDL-C: High Density Lipoprotein Cholesterol]. Adjusted P value is after multivariate regression analysis. Group 1; type 2 diabetes without nephropathy, Group 2; type 2 diabetes with nephropathy.

Table 1: Clinical characteristic of patients at baseline and after 36 months of ACEI/ARB therapy. 
Citation: Cheema BS, Kohli HS, Sharma R, Shah VN, lyengar S, et al. (2013) RAS Gene Polymorphisms and Renal Responsiveness to RAS Inhibition Therapy in Type 2 Diabetic Asian Indians. J Pharmacogenom Pharmacoproteomics 4: 114. doi:10.4172/2153-0645.1000114

\section{Genotyping}

Genomic DNA was isolated from peripheral blood lymphocytes using proteinase $\mathrm{K}$ digestion and phenol chloroform method. $A G T$ rs5050, AGT rs4762, AGT rs699 ACE rs4311, ACEI/D, ACE rs4343 and AGTR1 rs5186 SNPs were genotyped, as described by Ahluwalia et al. [15] (Supplementary Table 1). Positive and negative controls were used in each genotyping run, and 5\% of randomly selected samples were re-genotyped by other lab personnel with $100 \%$ concordance. The genotypes were also confirmed by randomly sequencing some of the samples.

\section{Risk score analysis}

A Risk score from 0-7 was calculated for each patient, based on the presence of number of variant alleles of studied polymorphisms. Their association with change in eGFR, UAE, serum creatinine levels in response to ACEI and ARB therapy was analyzed in both the groups. Genetic risk score using seven different SNPs in theory could vary between 0 and 14 risk alleles; however, as we counted the number of carriers instead of alleles, so the risk score varies between 0 and 7 .

\section{Statistical analysis}

The statistical tests were performed using the SPSS Inc.,Chicago, IL version 11.0. We tested the genotype and allele frequencies for deviation from Hardy-Weinberg equilibrium (HWE) proportions, by using Hardy-Weinberg equilibrium calculator. Using a chi-square test, the deviation of genotype distribution from HWE was considered significant at $\mathrm{P}<0.05$. Percentage increment or decrement are ratios and are considered as ordinal variables, so all statistical comparisons were performed with non-parametric test-the Kruskal-Wallis, and then using Bonferroni post-hoc test to indicate which group differs from the others. Wilcoxon t-test was used for the difference in delta values of means, before and after treatment. Power analysis was performed using Quanto (version 1.2; http://hydra.usc.edu/gxe). Positive associations observed between RAS genotype and ACEI and ARB blocker was adjusted for confounding factors using multivariate logistic regression, and this association persisted even after the influence of confounding factors, which include age, gender, HbA1c, duration of diabetes, duration of hypertension, smoking, systolic blood pressure and triglyceride levels was corrected. $\mathrm{p}<0.05$ was considered as statistical significant. Linkage disequilibria were also estimated for the polymorphisms in the study population, using haploview software (http://www.broad.mit.edu/mpg/ haploview/contact.php).

\section{Results}

\section{Clinical characteristics of patients at baseline and after 36 months of ACEI/ARB therapy}

A total of 810 patients completed the study. Diabetic patients with nephropathy (Group 2) were younger, had significantly longer duration of hypertension (HTN), had higher SBP, HbAlc and lower hemoglobin $(\mathrm{Hb})$, as compared to diabetic patients without nephropathy (Group
1). Number of patients taking sufonylurea ( $54.2 \%$ vs $35.1 \%, \mathrm{P}=0.0001$ ), metformin $(85.2 \%$ vs $59.3 \%, \mathrm{P}=0.0002)$ and pioglitazone $(40.1 \%$ vs $21.5 \%, \mathrm{P}<0.0001)$ were higher in Group I as compared to Group II. Use of insulin was common among patients with Group II as expected ( $31.2 \%$ vs $39.6 \%, \mathrm{P}=0.002)$.

Change in eGFR, urinary albumin excretion rate (UAE), serum creatinine levels at baseline and the end of 36 months of active treatment within Group 1 and Group 2 patients

Both Group 1 and Group 2 patients within Groups showed significant delta eGFR, UAE and serum creatinine at the end of 36 months of active treatment of ACEI/ARB therapy (Table 2).

\section{Association of polymorphisms with UAE, serum creatinine and eGFR}

Genotype distribution of the polymorphisms examined in the study population is summarized in supplementary table 2 . All the polymorphisms examined in the present study were in HWE in both the groups of patients. Baseline characteristics by genotype showed that patients with Group II had significantly higher initial baseline UAE and serum creatinine. LD values were generated to look for association among the three polymorphisms of the ACE and AGT genes. No significant $\mathrm{LD}$ was observed among either ACE or AGT variants $\left(\mathrm{r}^{2}\right.$ $<0.05$ for pair-wise comparison for the three polymorphisms of ACE and AGT genes).

\section{Percent change in eGFR, UAE, serum creatinine after ACEI and ARB treatment}

Group1 patients with II genotype (ACE I/D) showed greater percent decrease in UAE, serum creatinine and greater percent increase in eGFR ( $p=0.01$ ), with ACEI after 36 months (Figure 1). No significant difference in percent change in UAE, serum creatinine and eGFR were observed among Group 1 patients, based on (ACE I/D) genotypes with ARB after 36 months of therapy (Figure 2). In Group 2, patients with DD genotype (ACE I/D) showed greater percent decrease in UAE, serum creatinine, and greater percent increase in eGFR $(\mathrm{p}=0.008)$ with ARB after 36 months (Figure 2). However, there was no significant difference in percent change in UAE, serum creatinine and eGFR in these patients, based on (ACE I/D) genotypes with ACEI after 36 months (Figure 1). None of the other studied gene polymorphisms of ACE, AGT or AGT1R showed any significant association with percent change in UAE, serum creatinine and eGFR in patients on either ACEI and ARB therapy in both the groups (Supplementary Table 3).

\section{Effect of $A C E$ and $A G T$ gene haplotypes on clinical points}

Group 1 patients with haplotype T-D-G (alleles of rs4311, I/D, and rs4343) showed significantly lower percent change in UAE, serum creatinine and eGFR with ACEI $(\mathrm{p}=0.009)$, as compared to other haplotypes (C-I-G and C-I-A) (Figure 3). However, no significant difference in response to ARB was observed based on ACE haplotypes in these patients (Figure 4).

\begin{tabular}{|c|c|c|c|c|c|c|c|c|}
\hline & \multicolumn{4}{|c|}{ Group 1} & \multicolumn{4}{|c|}{ Group 2} \\
\hline & Before treatment & After treatment & $\Delta$ & $\mathrm{P}$ & Before treatment & After treatment & $\Delta$ & $\mathrm{P}$ \\
\hline eGFR (ml/min) & $98.3 \pm 19.8$ & $128.1 \pm 16.3$ & $30.2 \pm 19.1$ & 0.02 & $29.8 \pm 14.7$ & $76.8 \pm 24.6$ & $36.1 \pm 32.1$ & 0.02 \\
\hline S.Creatinine $(\mathrm{mg} \%)$ & $0.9 \pm 0.2$ & $0.6 \pm 0.1$ & $-0.3 \pm 0.2$ & 0.03 & $4.1 \pm 1.7$ & $2.5 \pm 1.4$ & $-1.6 \pm 1.6$ & 0.01 \\
\hline UAE & $70.1 \pm 50.2$ & $45.6 \pm 42.3$ & $-25.3 \pm 48.8$ & 0.009 & $1287.6 \pm 135.5$ & $771.3 \pm 125.6$ & $-514 \pm 132.2$ & 0.008 \\
\hline
\end{tabular}

$(p<0.05$ is significant). The difference in delta values of means before and after treatment was done using Wilcoxon t-test. Group 1: type 2 diabetes without nephropathy, Group 2: type 2 diabetes with nephropathy.

Table 2: Change in eGFR, urinary albumin excretion rate (UAE), serum creatinine levels at baseline and the end of 36 months of active treatment. 
Citation: Cheema BS, Kohli HS, Sharma R, Shah VN, lyengar S, et al. (2013) RAS Gene Polymorphisms and Renal Responsiveness to RAS Inhibition Therapy in Type 2 Diabetic Asian Indians. J Pharmacogenom Pharmacoproteomics 4: 114. doi:10.4172/2153-0645.1000114

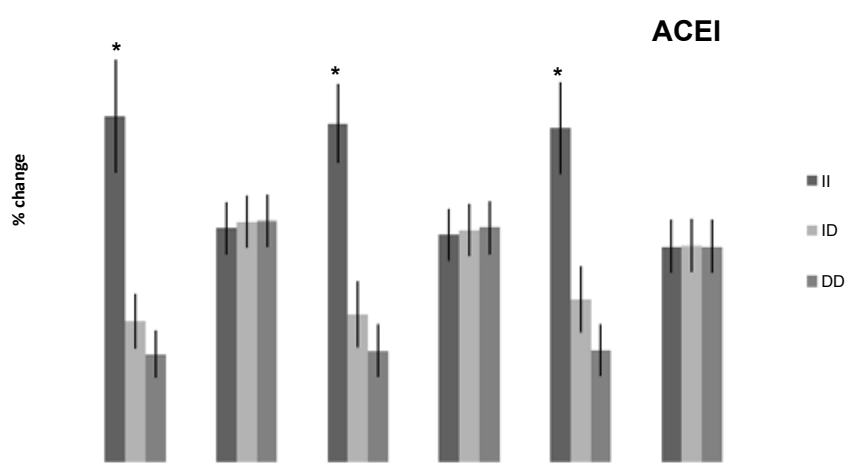

Values are given as mean \pm S.D. ${ }^{*} \mathrm{P}<0.05$; comparison within different genotypes was performed using one way Kruskal-Wallis, and then using Bonferroni post-hoc test. Group 1: type 2 diabetes without nephropathy, Group 2: type 2 diabetes with nephropathy.

Figure 1: Percent change in UAE, serum creatinine and eGFR after 36 months of ACEI therapy among the three genotypes, stratified by the presence or absence of nephropathy, based on ACEI/D genotypes.

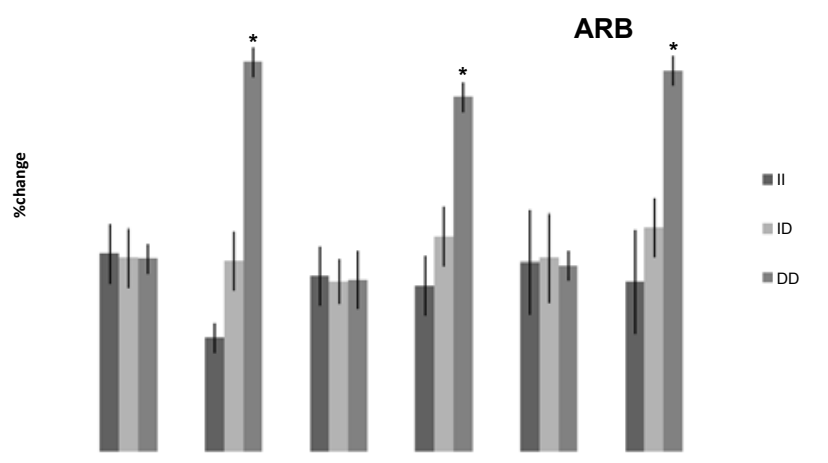

Values are given as mean \pm S.D. ${ }^{*} \mathrm{P}<0.05$; comparison within different genotypes was performed using one way Kruskal-Wallis, and then using Bonferroni post-hoc test. Group 1: type 2 diabetes without nephropathy, Group 2: type 2 diabetes with nephropathy.

Figure 2: Percent change in UAE, serum creatinine and eGFR after 36 months of ARB therapy among the three genotypes, stratified by the presence or absence of nephropathy, based on ACEI/D genotypes.

Group 2 patients with haplotype C-I-G (alleles of rs4311, I/D, and rs4343) showed significantly lower percent change in UAE, serum creatinine and eGFR after treatment with ARB ( $\mathrm{p}=0.01)$, as compared to other haplotypes (T-D-A and T-D-G) (Figure 4). However, no significant difference in response to ACEI based on ACE haplotypes was observed in this group (Figure 3).

No significant difference in response to ACEI and ARB was observed based on AGT haplotypes in both the groups.

\section{Cumulative effect of RAS gene variants on clinical points}

ACEI therapy: In Group 1 patients, those with risk score of zero or 1 , showed the maximum change in UAE, serum creatinine and eGFR after treatment with ACEI, as compared to those with $>1$ risk alleles ( $p=0.02$ ), whereas patients having a risk score of 7 showed minimum change in UAE, serum creatinine and eGFR after ACEI treatment. Further, Group 1 patients with risk score $>2$ showed significantly less percent change in UAE, serum creatinine and eGFR after treatment with ACEI, as compared to patients having 0 risk score $(\mathrm{p}=0.005)$. However, in Group 2 patients, no significant difference in response to ACEI was observed based on risk score (Figure 5).

ARB therapy: Group 2 patients with a risk score of $>6$ showed maximum change in UAE, serum creatinine and eGFR after ARB treatment $(\mathrm{p}=0.01)$, whereas patients with zero risk score showed minimum change in UAE, serum creatinine and eGFR after ARB treatment. Group 2 patients with a risk score of $>2$ showed significantly greater change in UAE, serum creatinine and eGFR after treatment with $\mathrm{ARB}$, as compared to patients having no risk allele $(\mathrm{p}=0.009)$. However, in Group 1 patients, no significant difference in response to ARB was observed based on risk score (Figure 6).

\section{Discussion}

An inter-individual variation in response to ACEI or ARB therapies is often observed, and it has been suggested that this may be partly genetically determined.

Our results suggest that $A C E \mathrm{I} / \mathrm{D}$ polymorphism was a significant modulator of response to ACEI and ARB therapy in our cohort of T2D patients, depending on their status of proteinuria. We observed that in normoalbuminuric T2D patients, renoprotective response to ACEI therapy was more effective in II genotype subjects. In contrast, in T2D patients with nephropathy and on ACEI, percent change in UAE, serum creatinine or eGFR was similar in all genotypes. Our results are consistent with findings from several studies in other ethnic groups, which also indicated that the anti-proteinuric response to ACEI was more favorable in patients with I allele [8-10]. However, our results differ from a study by $\mathrm{Ha}$ et al. [11], which showed that ACEI therapy decreased proteinuria more effectively in those with the DD, than in those with the II or ID genotype. However, the sample size was very small $(n=83)$ in this study, and it had very short duration of follow-up (3 months).

We also observed that ACE I/D genotype based differences in renal response to $\mathrm{ARB}$ were more pronounced in $\mathrm{T} 2 \mathrm{D}$ patients with

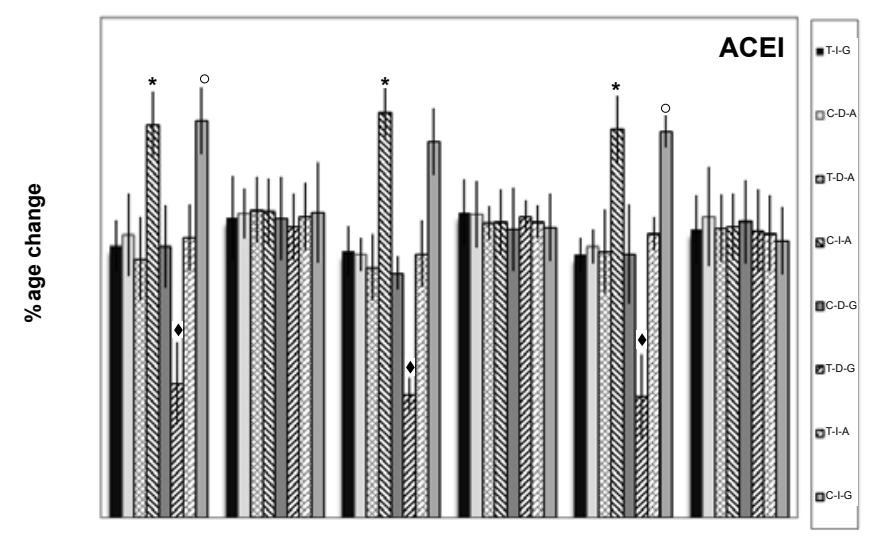

Values are given as mean \pm S.D. ${ }^{*}{ }^{*} \mathrm{P}<0.05$; comparison within different genotypes was performed using one way Kruskal-Wallis, and then using Bonferroni post-hoc test. (oT-I-G vs C-I-G, $\downarrow$ T-I-G vs T-D-G, ${ }^{*}$ T-I-G vs C-I-A).Group 1: type 2 diabetes without nephropathy, Group 2: type 2 diabetes with nephropathy.

Figure 3: Percent change in UAE, serum creatinine and eGFR after 36 months of ACEI therapy among the three haplotypes (alleles of rs4311, I/D, and rs4343), stratified by the presence or absence of nephropathy. 
Citation: Cheema BS, Kohli HS, Sharma R, Shah VN, lyengar S, et al. (2013) RAS Gene Polymorphisms and Renal Responsiveness to RAS Inhibition Therapy in Type 2 Diabetic Asian Indians. J Pharmacogenom Pharmacoproteomics 4: 114. doi:10.4172/2153-0645.1000114

Page 5 of 7

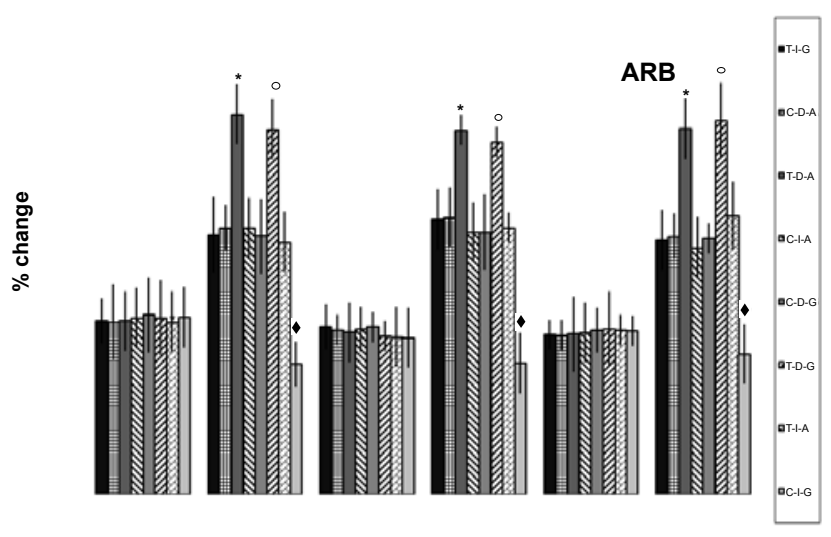

Values are given as mean \pm S.D. ${ }^{* *} \mathrm{P}<0.05$; comparison within different genotypes was performed using one way Kruskal-Wallis, and then using Bonferroni post-hoc test. (oT-I-G vs C-I-G, $\bullet$ T-I-G vs T-D-G, *T-I-G vs C-I-A).Group 1: type 2 diabetes without nephropathy, Group 2: type 2 diabetes with nephropathy.

Figure 4: Percent change in UAE, serum creatinine and eGFR after 36 months of ARB therapy among the three haplotypes (alleles of rs4311, I/D, and rs4343), stratified by the presence or absence of nephropathy.

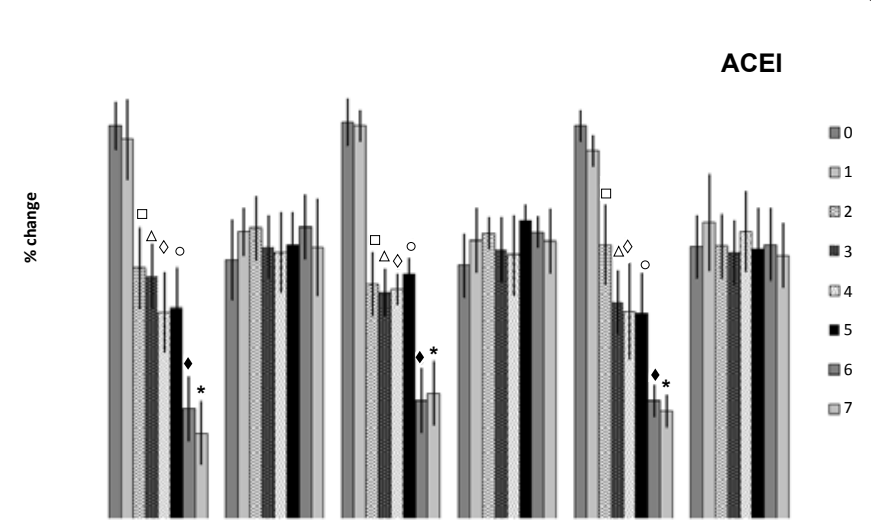

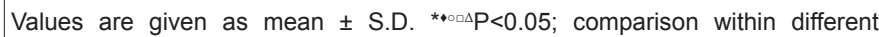
genotypes was performed using one way Kruskal-Wallis, and then using Bonferroni post-hoc test. ( $\square$ Zero risk score vs 2 risk score, $\Delta$ zero risk score vs 3 risk score, $\oslash$ zero risk score vs 4 risk score, ozero risk score vs 5 risk score, -zero risk score vs 6 risk score, *zero risk score vs 7 risk score). Group 1: type 2 diabetes without nephropathy, Group 2: type 2 diabetes with nephropathy.

Figure 5: Percent change in UAE, serum creatinine and eGFR after 36 months of ACEI therapy among the seven risk scores, stratified by the presence or absence of nephropathy.

nephropathy, as compared to patients with normoalbuminuria: DD and ID genotype carriers with proteinuria showed better beneficial response to nearly all endpoints, as compared to II genotype carriers. These results are consistent with those reported by Parving et al. [19], who also observed that $\mathrm{D}$ allele was associated with better response to angiotensin II blockade in T2D with overt nephropathy. However, Andersen et al. [13] and Haneda et al. [14] have reported no association between $A C E$ $\mathrm{I} / \mathrm{D}$ polymorphism, and reduction in treatment-induced proteinuria in T2D and overt nephropathy. These differences could be attributed to small sample size and ethnic differences between the studied cohorts. Thus, our results suggest that $A C E$ genotypes may be a good marker for clinical efficacy of ACEI and ARB in DN. A plausible explanation for these observations may be that different ACE I/D genotypes may affect renal hemodynamics to a different extent, resulting in differential response to RAS blockade. For example, ACEI reduce glomerular capillary hydraulic pressure more effectively in patients with the II, than in those with the DD genotype. It has been suggested that in II carriers, decreased glucose-induced pre-glomerular vasodilatation and less severe hyperfiltration might amplify the long-term protective effect of ACEI therapy against development and progression of nephropathy $[23,24,17]$. ACE I/D is in non coding region, which makes it unlikely to be a functional variant, but several studies suggest that it may be in close linkage disequilibrium (LD), with a quantitative trait loci (QTLs) controlling ACE levels [25,26]. Recent data also indicate that ACE expression may also be under epigenetic control [27].

We found no significant association of AGT and AGTR1 gene polymorphisms, with response to ACEI and ARB therapy in our cohort. This is in contrast to the observations by Narita et al. [21] and Konoshita [22], who reported that AGT haplotypes and AGTR1 A1166 C polymorphism could influence the therapeutic efficacy of a RAS blockade in nephropathy patients. This may be due to the different phenotypes of nephropathy patients, study design and duration of follow-up in these studies.

It has been suggested that haplotype approach to study common variations within relevant candidate genes is more likely to unravel any existing pharmacogenetic associations in multiple RAS genes, and their relation to ACE I and ARB treatment benefit. For example, Zhu et al. [28] showed an epistatic interaction between ACE variants (rs4311 $\mathrm{T} / \mathrm{C}$ ), and in (rs4343 A/G), in modulating blood pressure, and Su et al. [29] reported that two haplotypes of AGTR1 were associated with blood pressure reduction, in response to benazepril. Our results showed that $A C E$ gene haplotypes were a significant modulator of response to ACEI and ARB therapy in T2D patients, depending on the status of proteinuria. The risk haplotypes may reflect a specific combination of SNPs that controls inter individual variation in response to ACEI or ARB therapies, depending on the status of proteinuria. SNPs associated with these specific haplotypes may be in linkage disequilibrium with some functional polymorphism that directly influence clinical efficacy of ACEI and ARB therapy, depending on the status of proteinuria.

We also analysed synergestic/additive effect of multiple SNPs in the

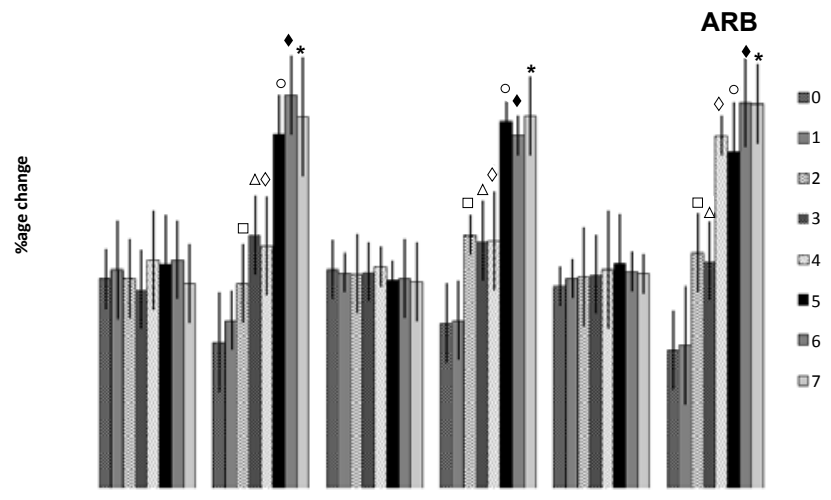

Values are given as mean \pm S.D. ${ }^{*} \circ \square \Delta \mathrm{P}<0.05$; comparison within different genotypes was performed using one way Kruskal-Wallis, and then using Bonferroni post-hoc test. ( $\square$ Zero risk score vs 2 risk score, azero risk score vs 3 risk score, $\diamond$ zero risk score vs 4 risk score, ozero risk score vs 5 risk score, zero risk score vs 6 risk score, *zero risk score vs 7 risk score). Group 1: type 2 diabetes without nephropathy, Group 2: type 2 diabetes with nephropathy.

Figure 6: Percent change in UAE, serum creatinine and eGFR after 36 months of ARB therapy among the seven risk scores, stratified by the presence or absence of nephropathy. 
Citation: Cheema BS, Kohli HS, Sharma R, Shah VN, lyengar S, et al. (2013) RAS Gene Polymorphisms and Renal Responsiveness to RAS Inhibition Therapy in Type 2 Diabetic Asian Indians. J Pharmacogenom Pharmacoproteomics 4: 114. doi:10.4172/2153-0645.1000114

Page 6 of 7

RAS genes for pharmacogenetic associations, in relation to ACEI and ARB in T2D patients. For this, we calculated a risk score in each patient, based on the presence of risk alleles of the RAS gene polymorphisms genotyped in our study. We observed that response to ACEI /ARB was associated with the number of risk alleles carried by an individual patient; patients with no or 1 risk allele with normoalbuminuria showed greater reduction in UAE, serum creatinine, and better preservation of eGFR with ACEI therapy. In patients with nephropathy, response to ACEI was not influenced by the number of risk alleles carried by an individual patient. However, response to ARB was better in those with risk score of 6 or 7 in micro /macroalbuminuric patients. To date, there is no published data on association of synergestic/additive effect of multiple SNPs in the RAS genes, with antiproteinuric response to ACEI and ARB therapy. Thus, our is the first results suggesting that the risk score analysis may be a good marker for clinical efficacy of ACEI and $\mathrm{ARB}$ therapy in $\mathrm{T} 2 \mathrm{D}$ patients, depending on the status of proteinuria.

There are several strengths and some limitations of our study: we had ethnically homogenous diabetic subjects who were enrolled from a single center, thus avoiding phenotyping errors and bias. No regional differences in disease prevalence or allele frequency were observed between the two recruitment sites (Department of Endocrinology and Department of Nephrology, Post Graduate Institute of Medical Education and Research, Chandigarh). Also, as patients were seen at a tertiary hospital, they were well phenotyped, and could be followed for a long time.

The sample size was predetermined for studied variants to have a minimum power of $85 \%$ (power ranged from $86 \%-94 \%$ for selected polymorphisms of RAS), at a small effect size (0.1) and alpha level (0.05). Positive associations observed between RAS genotype and ACEI and ARB blocker do not seem to be due to chance, as this association persisted even after the influence of confounding factors was corrected. A limitation of our study might be that instead of prescribing any single ACEI (e.g. captopril, enalapril, lisinopril, ramipril) or ARB (e.g. telmisartan, valsartan, losartan, irbesartan) drug at a fixed dose, we rather checked reno-protective response to any ACEI and ARB therapy, which suggest that pharmacokinetic differences between individuals could also account for some variability in responsiveness. Moreover, as patients who switched medication were excluded from the study, the current analysis tends to favor well-responding patients. Also, response to treatment using risk scores was developed as an attempt at trying to quantify a polygenic association; however, an important limitation of this attempt is it assumes that each risk allele was given an identical effect size, which might affect the outcome of our results.

\section{Conclusion}

Our results suggest that $A C E$ genotypes individually, and in interaction with other RAS single-nucleotide polymorphisms may be a good marker for clinical efficacy of ACEI and ARB therapy in T2D patients, depending on the status of proteinuria.

\section{Acknowledgement}

The study was carried out at Genomics Laboratory, PGIMER, Chandigarh India. We are grateful to the volunteers of this study, the laboratory staff, and all who gave their time to take part in this study. No competing financial conflict of interest exists. All authors reviewed the manuscript. Prof. Madhu Khullar is the guarantor of this work and as such, had full access to all data in the study, and takes responsibility for the integrity of the data and the accuracy of the data analysis.

\section{References}

1. US Renal Data System, USRDS (2012) Annual Data Report: Atlas of Chronic Kidney Disease and End-Stage Renal Disease in the United States, National
Institutes of Health, National Institute of Diabetes and Digestive and Kidney Diseases, Bethesda, USA.

2. Gross JL, de Azevedo MJ, Silveiro SP, Canani LH, Caramori ML, et al. (2005) Diabetic nephropathy: diagnosis, prevention, and treatment. Diabetes Care 28 164-176.

3. Seaquist ER, Goetz FC, Rich S, Barbosa J (1989) Familial clustering of diabetic kidney disease. Evidence for genetic susceptibility to diabetic nephropathy. $\mathrm{N}$ Engl J Med 320: 1161-1165.

4. Earle K, Walker J, Hill C, Viberti G (1992) Familial clustering of cardiovascular disease in patients with insulin-dependent diabetes and nephropathy. $\mathrm{N}$ Engl J Med 326: 673-677.

5. Quinn M, Angelico MC, Warram JH, Krolewski AS (1996) Familial factors determine the development of diabetic nephropathy in patients with IDDM. Diabetologia 39: 940-945.

6. Casas JP, Chua W, Loukogeorgakis S, Vallance P, Smeeth L, et al. (2005) Effect of inhibitors of the renin-angiotensin system and other antihypertensive drugs on renal outcomes: systematic review and meta-analysis. Lancet 366 : 2026-2033.

7. Rigat B, Hubert C, Alhenc-Gelas F, Cambien F, Corvol P, et al. (1990) An insertion/deletion polymorphism in the angiotensin I-converting enzyme gene accounting for half the variance of serum enzyme levels. J Clin Invest 86: 13431346.

8. Penno G, Chaturvedi N, Talmud PJ, Cotroneo P, Manto A, et al. (1980) Effect of angiotensinconverting enzyme (ACE) gene polymorphism on progression of renal disease and the influence of ACE inhibition in IDDM patients: findings from the EUCLID Randomized Controlled Trial. EURODIAB Controlled Trial of Lisinopril in IDDM. Diabetes 47: 1507-1511.

9. Parving HH, Jacobsen P, Tarnow L, Rossing P, Lecerf L, et al. (1996) Effect of deletion polymorphism of angiotensin converting enzyme gene on progression of diabetic nephropathy during inhibition of angiotensin converting enzyme: observational follow up study. BMJ 313: 591-594.

10. So WY, Ma RC, Ozaki R, Tong PC, Ng MC, et al. (2006) Angiotensin-converting enzyme (ACE) inhibition in type 2, diabetic patients--interaction with ACE insertion/deletion polymorphism. Kidney Int 69: 1438-1443.

11. Ha SK, Yong Lee S, Su Park H, Ho Shin J, Jung Kim S, et al. (2000) ACE DD genotype is more susceptible than ACE II and ID genotypes to the antiproteinuric effect of ACE inhibitors in patients with proteinuric non-insulindependent diabetes mellitus. Nephrol Dial Transplant 15: 1617-1623.

12. Andersen S, Tarnow L, Cambien F, Rossing P, Juhl TR, et al. (2002) Renoprotective effects of losartan in diabetic nephropathy: interaction with ACE insertion/ deletion genotype? Kidney Int 62: 192-198.

13. Andersen S, Tarnow L, Cambien F, Rossing P, Juhl TR, et al. (2003) Long-term renoprotective effects of losartan in diabetic nephropathy: interaction with ACE insertion/deletion genotype? Diabetes Care 26: 1501-1506.

14. Haneda M, Kikkawa R, Sakai H, Kawamori R (2004) Antiproteinuric effect of candesartan cilexetil in Japanese subjects with type 2 diabetes and nephropathy. Diabetes Res Clin Pract 66: 87-95.

15. Ahluwalia TS, Ahuja M, Rai TS, Kohli HS, Bhansali A, et al. (2009) ACE variants interact with the RAS pathway to confer risk and protection against type 2 diabetic nephropathy. DNA Cell Biol 28: 141-150.

16. Jacobsen P, Tarnow L, Carstensen B, Hovind P, Poirier O, et al. (2003) Genetic variation in the Renin-Angiotensin system and progression of diabetic nephropathy. J Am Soc Nephrol 14: 2843-2850.

17. Ruggenenti P, Bettinaglio P, Pinares F, Remuzzi G (2008) Angiotensin converting enzyme insertion/deletion polymorphism and renoprotection in diabetic and nondiabetic nephropathies. Clin J Am Soc Nephrol 3: 1511-1525.

18. Brenner BM, Cooper ME, de Zeeuw D, Grunfeld JP, Keane WF, et al. (2000) The losartan renal protection study: rationale, study design and baseline characteristics of RENAAL (Reduction of Endpoints in NIDDM with the Angiotensin II Antagonist Losartan). J Renin Angiotensin Aldosterone Syst 1: 328-335.

19. Parving HH, de Zeeuw D, Cooper ME, Remuzzi G, Liu N, et al. (2008) ACE gene polymorphism and losartan treatment in type 2 diabetic patients with nephropathy. J Am Soc Nephrol 19: 771-779.

20. Dragovic T, Ajdinovic B, Hrvacevic R, llic V, Magic Z, et al. (2010) Angiotensin I 
Citation: Cheema BS, Kohli HS, Sharma R, Shah VN, Iyengar S, et al. (2013) RAS Gene Polymorphisms and Renal Responsiveness to RAS Inhibition Therapy in Type 2 Diabetic Asian Indians. J Pharmacogenom Pharmacoproteomics 4: 114. doi:10.4172/2153-0645.1000114

type 1 receptor gene polymorphism could influence renoprotective response to losartan treatment in type 1 diabetic patient with high urinary albumin excretion rate. Vojnosanit Pregl 67: 273-278.

21. Narita I, Goto S, Saito N, Song J, Omori K, et al. (2003) Angiotensinogen gene variation and renoprotective efficacy of renin-angiotensin system blockade in IgA nephropathy. Kidney Int 64: 1050-1058.

22. Konoshita T (2011) Do genetic variants of the Renin-Angiotensin system predict blood pressure response to Renin-Angiotensin system-blocking drugs? A systematic review of pharmacogenomics in the Renin-Angiotensin system. Curr Hypertens Rep 13: 356-361.

23. Wang Y, Ng MC, So WY, Tong PC, Ma RC, et al. (2005) Prognostic effect of insertion/deletion polymorphism of the ace gene on renal and cardiovascular clinical outcomes in Chinese patients with type 2 diabetes. Diabetes Care 28: 348-354.

24. Weekers L, Bouhanick B, Hadjadj S, Gallois Y, Roussel R, et al (2005) Modulation of the renal response to ACE inhibition by ACE insertion/deletion polymorphism during hyperglycemia in normotensive, normoalbuminuric type 1 diabetic patients. Diabetes 54: 2961-2967.
25. Villard E, Tiret L, Visvikis S, Rakotovao R, Cambien F, et al. (1996) Identification of new polymorphisms of the angiotensin l-converting enzyme (ACE) gene and study of their relationship to plasma ACE levels by two-QTL segregationlinkage analysis. Am J Hum Genet 58: 1268-1278.

26. McKenzie CA, Sinsheimer JS, Adeyemo AA, Cox RD, Southam L, et al. (2005) SNP haplotypes in the angiotensin l-converting enzyme (ACE) gene: analysis of Nigerian family data using gamete competition models. Ann Hum Genet 69 : 227-232.

27. Rivière G, Lienhard D, Andrieu T, Vieau D, Frey BM, et al. (2011) Epigenetic regulation of somatic angiotensin-converting enzyme by DNA methylation and histone acetylation. Epigenetics 6: 478-489.

28. Zhu X, Chang YP, Yan D, Weder A, Cooper R, et al. (2003) Associations between hypertension and genes in the renin-angiotensin system. Hypertension 41 1027-1034.

29. Su X, Lee L, Li X, Lv J, Hu Y, et al. (2007) Association between angiotensinogen, angiotensin II receptor genes, and blood pressure response to an angiotensinconverting enzyme inhibitor. Circulation 115: 725-732. 